\title{
UNPICKING THE BARRIERS TO DIVERSITY IN ENGINEERING APPRENTICESHIPS
}

\author{
Tania HUMPHRIES-SMITH ${ }^{1}$, Matthew WHITE ${ }^{2}$ and Clive HUNT $^{3}$ \\ ${ }^{1 \& 3}$ Bournemouth University \\ ${ }^{2}$ Bournemouth \& Poole College
}

\begin{abstract}
The study reported in this paper investigated some of the barriers to increasing diversity in those taking up engineering apprenticeships. Specifically, the papers report an investigation of progression opportunities for level 2 and 3 engineering design apprentices from disadvantaged backgrounds studying on the south coast of the UK. The outcome of the investigation lead to a series of interventions being made with both the companies employing apprentices and the section of the local Further Education college responsible for recruitment for all engineering apprentices in the local area. The impact of the study has led to a significant increase (from $11 \%$ to $26 \%$ ) of apprentices from disadvantaged backgrounds entering level 2 technical qualifications in Sept 2017 which provide them with progression opportunities to Higher Education at level 4 and beyond. The interventions also lead a raising of awareness of the imbalance of backgrounds of students. This has led to a more systemised and rigorous approach to career/progression pathway advice to apprenticeship applicants within the college.
\end{abstract}

\section{Keywords: Apprenticeships, Engineering, Diversity, Skills Shortages, Widening Participation}

\section{INTRODUCTION}

This paper reports on a series of interventions, that were made to improve the progression opportunities of engineering design apprentices from disadvantaged backgrounds, defined by postcode data, studying at a further education (FE) college, on the south coast of the UK. Earlier research reported in HumphriesSmith et al [1] and Humphries-Smith and Hunt [2] determined that progression to level 4 study showed an almost total domination by white middle class males, while progression by those from disadvantaged backgrounds, determined by postcode data as being less than $10 \%$. Similar quantitative research, at the same FE college, on the backgrounds of Higher National Certificate (HNC) and level 2 \& 3 apprentices [3], showed that students from lower socio-economic backgrounds were more likely to study craft qualifications rather than technical qualifications that can lead to higher education progression. The reverse was seen from students from middle and upwards socio-economic backgrounds. Throughout this paper, the educational levels referred to, e.g. level 3, are those defined by the UK Government [4]. First delivered in 2012/13, the particular FE college identified works in partnership with a local university to provide an integrated programme from completing an advanced/level 3 apprenticeship through HNC, Foundation Degree in Engineering (FdEng), BEng to graduate with an MEng honours degree. This has resulted in around two-thirds of apprentices studying at level 3 making the transition to level 4 and thus higher education, which is significantly more than the national average of less than $40 \%$. The programme is now part of both Higher and Degree Apprenticeships, with total apprenticeship numbers (including Advanced and Higher) at the FE college and associated university being around 500 .

As all these apprentices are employed in the engineering sector, and as the content of the Advanced, Higher and Degree Apprenticeships are determined by industry, there is a direct link with the theme of industrial involvement with design and engineering education.

The aims of the research were:

Phase 1

Determine the backgrounds of current level $2 \& 3$ engineering apprentices at the FE college

Determine how the choice of which courses were taken as part of apprenticeship was made and by whom 
Determine the backgrounds of first year HNC students for this academic year by re-running the questionnaire used last academic year to gain longitudinal data.

Determine the decision making strategies used by employers to select apprentices and the courses taken Phase 2

Design and implement an intervention to increase the number of those from disadvantaged backgrounds entering the HNC, and thus, Higher Education commencing at level 4.

\section{LITERATURE REVIEW}

The skills shortage in the engineering sector has been long established but the IET Engineering and Technology Skills and Demand in Industry 2017 report [5] suggests that

"fewer than one in ten businesses $(9 \%)$ take particular actions to increase...diversity of their workforces." p6

This is despite the most recent report Engineering UK 2017 Report [6] (p6), suggesting there "to be a shortfall of between 37,000 to 59,000 in meeting an annual demand for 124,000 core engineering roles requiring level 3+ skills including a graduate level shortfall of at least 22,000 per year. Fuller [8] identifies that this is also recognised nationally by Government and the Sutton Trust and points out that there are a disproportionately lower number of apprentices from disadvantaged backgrounds (as defined by Office for Students POLAR3 analysis and free school meals). She explains that,

"those from disadvantaged backgrounds - especially men - are less likely to start an apprenticeship, [but] the percentage of disadvantaged men who start advanced apprenticeships is the same as those with university degrees. For this cohort, the percentage of men and women with an advanced apprenticeship who were eligible to receive free school meals when at school is $7 \%$ and $11 \%$ respectively." p7

In their work, Kashefpakdel and Rehil [9] identify that apprenticeships are considered to be the "poor relative' [p17] compared to degree study at university, which suggests there might be an issue related to the image of apprenticeship schemes. They also suggest there is a link with apprenticeship and lower academic attainment and identify that the majority of people applying for an apprenticeship come from families where neither parent had gone to university. However, while this may be true for intermediate apprenticeships (level 2) it is not the case for those directly entering an advanced (level 3) apprenticeship. In considering the significant differences between industrial sectors Fuller [8] found that the engineering sector has the highest number of advanced apprenticeships in contrast to the service sectors where there is a dominance of intermediate apprenticeships. Fuller [8] makes the point that "there is much more 'selection"” by companies for employees qualified to level 3 and she identifies that those level 3 apprentices are much less likely to have received free school meals than their peers. She goes on to point out that for students entering the degree apprenticeships in engineering, accountancy or project management is an attractive option for these young people is strong. Their schools have delivered the necessary qualifications, social capital and networks that can help to facilitate access to the most competitive apprenticeships offered by top employers, and comments that

"for this group, completion of a degree apprenticeship is an alternative route to a successful career, consolidating their social position." p35

The importance of social capital is confirmed by Hunt, et al, [10], in their research that investigated the factors that influenced first- and second-generation design and engineering students to attend university, point out that social capital cannot be underestimated and describe it as a 'continuum' (p40) of peoples' lives. For middle-class students, their desire to study beyond school is often seen as a natural progression but it is often a non-choice for many working-class students, as they see it as not being for them. In their work, Brockmann and Laurie [11] contrast the attitudes of apprentices on a 'craft' apprenticeship in motor vehicle maintenance with ones on a 'technical' apprenticeship in engineering and report significant differences in background with those on the technical apprenticeship having good academic school backgrounds and good grades with a number rejecting a university place in favour of the apprenticeship and seeing the apprenticeship as the start of a career. Whereas, those on the craft apprenticeship saw themselves as being practical and vocational with little appetite for progression.

Fuller [8] also recognises the value of social capital and stresses that there should be a seamless progression for those beginning on lower level apprenticeships to those that are higher. She comments that 
"Level 2 and 3 apprentices should not hit arbitrary glass ceilings and have similar chances as their A-level or graduate peers to access the next level, including higher and degree apprenticeships." $\mathrm{p} 4$.

Brockmann and Laurie [11] echo this view and identify that there is a need to address the academic vocational divide and provide progression routes.

\section{METHODOLOGY}

A qualitative methodology was adopted for this research; however, some quantitative data was collected. Qualitative data collection methods included interviews undertaken with a number of companies, employing level 2 and 3 apprentices, to understand their processes and perceptions of the recruitment process in March/April 2017. Qualitative data was also collected from the FE college's careers advice and apprentice recruitment section, Curriculum Leaders and Apprenticeships Manager to further develop an understanding of progression opportunities. An intervention was then designed and implemented in June 2017.

Both quantitative and qualitative data, related to the apprentices' backgrounds, was collected via questionnaire to apprentices on levels $2,3 \& 4$ and via anonymised student records for those entering in Sept 2017. The data requested replicated that taken for Sept 2016 intake, previously reported [1] and included: gender, ethnicity, age, Senior school attended, GCSEs obtained, occupation of parent/guardian, whether respondent had free school meals, post code of domicile while at school. The study used POLAR3 quintile data to analyse postcode of domicile while at school (using the Office for Students Postcode Checker available at https://www.officeforstudents.org.uk/data-andanalysis/postcode-search/ . POLAR3 quintiles [7] indicate the likelihood of a young person from a specific postcode participating in higher education with quintile 5 being most likely and quintile 1 least likely. Hence, a direct comparison was possible and allowed for some determination of possible effect of the intervention.

These apprentices are variously studying qualifications at level 2 City \& Guilds (C\&G) craft; level 2 C\&G Technical Certificates (Tech); level 3 C\&G; level 3 Business and Technology Education Council (BTEC) and level 3 subsidiary diploma (SD) and level4 HNC.

Ethical approval was sought prior to the commencement of the study and ensured all participation was voluntary with individuals being free to withdraw at any time. Anonymity has also been fully maintained throughout the research.

\section{OUTCOMES AND DISCUSSION}

Quantitative and qualitative outcomes are presented and discussed in this section.

\subsection{Decision making process}

To understand and develop a model of the decision-making process, in the pathway through apprenticeship, interviews were held with 5 companies that recruit apprentices in March/April 2017. In summary, the choice of which level of apprenticeship is recruited to is based upon a combination of previous qualifications and requirements of business. However, there was some confusion among the firms interviewed about what course, and level, the apprentice was enrolled upon and generally this was said to be the decision of the college. All companies recruited via the FE college and some used apprentice fairs and other agencies such as the EEF (formally the Engineering Employers Federation). This meant that the companies all relied on the college to undertake the initial screening of potential apprentices for them. Therefore, it was key that the college screening process fitted the company requirements fully and went beyond just supplying CVs from potential apprentice applicants. All employers used some form of interview as well as the initial scrutiny of CV and qualifications. All were looking for good maths and science results at GCSE, normally $\mathrm{C}$ or above and most would consider recruitment of apprentices with A levels. The companies also relied on the college to undertake initial maths, English and engineering competency assessments; so that they got a more rounded understanding of their level than just their exam results. Most also talked about being interested in the attitude/character of the applicant, which they determined through interview. None considered the school attended or the postcode of domicile (except for transport reasons). Parental or family occupation and history was considered by some companies, but only in helping to determine an interest, or the relevance of engineering within their life. Thus, none gave consideration to the fact that some applicants may perform less well at interview or have lesser qualifications because of their background. Although, one company 
did recognise that they got applications to different levels of apprenticeship from different schools, and for applications to level 2 apprenticeships, were prepared to recognise that the applicant may not have reached their full potential at GCSEs. This finding falls in line with the outcomes of the IET survey [4].

\subsection{Intervention}

An intervention to increase the number of apprentices from disadvantaged backgrounds entering the HNC at the FE college started in the form of a meeting, in June 2017, with the apprenticeship recruitment centre (who process all applicants for engineering apprentices and are instrumental in the decisionmaking process) at the FE college; to discuss guidance given to applicants and employers. This meeting highlighted that the apprenticeship recruitment centre and Curriculum Leaders had only recently really understood the progression pathways through to $\mathrm{HNC}$ and were for the intake starting Sept 2017 offering a more rigorous level of guidance to applicants. It is also clear that subsequent to the process of matching applicants with apprenticeships, there is input from the Curriculum Leaders and a more joined up approach is required to ensure progression pathways are appropriate. As a result, the college changed the method that it undertook for the screening process. Instead of sending adverts for apprenticeship positions directly to potential applicants and letting them apply to specific companies, a general application form was completed, and an assessment process undertaken to judge their level for maths, English and technical understanding, alongside a formal interview. From this they were sent the apprenticeship positions that best suited their capability, not just what they thought they could do. The intention of this was to reduce the tendency for applicants to apply for the type of apprenticeship, be it craft or technical, that their background favours, rather than what their qualifications and capability enable them to apply for. Therefore, increasing and enhancing the pool of potential jobs for the applicants and number of apprentices for the companies. Since this process has been adopted there have been follow up discussions with local companies on how they promote their engineering apprenticeships. A second stage meeting took place in December 2017; to ensure that there was a full understanding about the requirements and opportunities offered by the Degree Apprenticeship; so that the matching of applicants to companies could be further refined.

However, it also highlighted that the careers guidance in many schools was considered poor with staff lacking knowledge about engineering and apprenticeships, this was exacerbated by the fact that many schools had stopped offering work experience in year 10. As a direct result of this, the college and university have been working with the economic development section of the local councils on the delivery of apprenticeship events, promoting apprenticeship vacancies within schools and STEM focused CPD events for teachers. Issues with careers guidance in schools have been recognised by the Government and this has resulted in a new Careers Strategy being published in Dec 2017 [12] which is currently being implemented. The strategy puts the responsibility for careers guidance on individual schools but also introduces the notion of Enterprise Advisors, sourced by the Careers Guidance Company, who are from local industry thus, reducing reliance upon teaching staff. It is reported [12] that the network at time of publication was operating in half of secondary schools.

Also, as a result of the perceived image of apprenticeship schemes, two companies have decided that their apprenticeship programmes needed to be updated and made more relevant, to appeal to a wider range to potential applicants, from a wider range of schools and backgrounds. Both have selected current Degree Apprentices, who have already completed an Advanced Apprentice, to undertake a research and implementation project as part of this redevelopment. This is enabling them to apply their hands-on knowledge and understanding, alongside the skills and behaviours requirements of the apprenticeship; to hopefully attract a wider consortium of applicants.

\subsection{Data related to backgrounds of level 2, 3, \& 4 apprentices}

From Table 1 it can be seen that for entry in Sept 2016 for C\&G Tech, SD \& BTEC between 11-15\% of apprentices are classed as being in POLAR3 quintile 1 contrast this with level 2 C\&G Marine where $46 \%$ are classed as being in POLAR3 quintile 1. 22\% on level 2 C\&G Engineering Manufacture are classed as POLAR3 quintile 1. This suggests there is firstly, a difference in the backgrounds of those apprentices entering $\mathrm{C} \& \mathrm{G}$ craft courses compared to $\mathrm{C} \& \mathrm{G}$ Tech and BTEC technical courses, and secondly, there is some difference in the backgrounds of apprentices entering $\mathrm{C} \& \mathrm{G}$ craft courses dependent upon the subject. Qualitative data was also collected on careers advice which indicates overwhelmingly young people entering level 4 study in engineering have a family member already in some form of engineering and got careers advice from family - to note here $61 \%$ of those progressing 
to level $4 \mathrm{HNC}$ have parents/carers with class 1 or 2 occupations. This finding would appear to confirm that of Hunt et al [10] related to social capital.

Table 1. Comparison of Apprentices Backgrounds entry Sept 2016 to Sept 2017

\begin{tabular}{|c|c|c|c|c|c|c|c|c|c|c|c|c|c|c|}
\hline & \multicolumn{2}{|c|}{$\begin{array}{c}\text { Level } 4 \\
\text { HNC1 }\end{array}$} & \multicolumn{2}{|c|}{$\begin{array}{c}\text { Level } 3 \\
\text { SD }\end{array}$} & \multicolumn{2}{|c|}{$\begin{array}{l}\text { Level } 3 \\
\text { BTEC }\end{array}$} & \multicolumn{2}{|c|}{$\begin{array}{l}\text { Level } 2 \\
\text { C\&G } \\
\text { Tech }\end{array}$} & \multicolumn{2}{|c|}{$\begin{array}{l}\text { Level } 3 \\
\text { C\&G } \\
\text { Marine }\end{array}$} & \multicolumn{2}{|c|}{$\begin{array}{l}\text { Level } 2 \\
\text { C\&G } \\
\text { Marine }\end{array}$} & \multicolumn{2}{|c|}{$\begin{array}{c}\text { Level } 2 \\
\text { C\&G } \\
\text { EngMfg }\end{array}$} \\
\hline Date Sept & 16 & 17 & 16 & 17 & 16 & 17 & 16 & 17 & 16 & 17 & 16 & 17 & 16 & 17 \\
\hline Respondents & 64 & 44 & 11 & 11 & 117 & 126 & 56 & 42 & 27 & 18 & 52 & 42 & 79 & 65 \\
\hline POLAR3 Q1 & $11 \%$ & $14 \%$ & $9 \%$ & $9 \%$ & $15 \%$ & $19 \%$ & $11 \%$ & $26 \%$ & $22 \%$ & $16 \%$ & $46 \%$ & $33 \%$ & $22 \%$ & $25 \%$ \\
\hline POLAR3 Q2 & $23 \%$ & $25 \%$ & $9 \%$ & $18 \%$ & $11 \%$ & $16 \%$ & $21 \%$ & $33 \%$ & $15 \%$ & $8 \%$ & $23 \%$ & $36 \%$ & $18 \%$ & $31 \%$ \\
\hline POLAR3 Q3 & $36 \%$ & $25 \%$ & $45 \%$ & $9 \%$ & $42 \%$ & $35 \%$ & $20 \%$ & $21 \%$ & $33 \%$ & $50 \%$ & $21 \%$ & $12 \%$ & $32 \%$ & $17 \%$ \\
\hline POLAR3 Q4 & $23 \%$ & $23 \%$ & $36 \%$ & $36 \%$ & $22 \%$ & $19 \%$ & $23 \%$ & $12 \%$ & $22 \%$ & $8 \%$ & $4 \%$ & $7 \%$ & $15 \%$ & $22 \%$ \\
\hline POLAR3 Q5 & $20 \%$ & $7 \%$ & & $18 \%$ & $8 \%$ & $11 \%$ & $23 \%$ & $7 \%$ & $7 \%$ & $4 \%$ & $0.5 \%$ & $1 \%$ & $13 \%$ & $5 \%$ \\
\hline
\end{tabular}

In contrast for entry in Sept 2017 there was a significant increase $(11-26 \%)$ of apprentices from POLAR3 Q1 entering level 2 C\&G Tech Engineering along with a small increase in number of apprentices from POLAR3 Q1 entering the HNC. There was a converse decrease in apprentices from POLAR3 Q1 entering level $2 \mathrm{C} \& \mathrm{G}$ Marine. It would be reasonable to suggest that these changes are in large part related to the better understanding developed at apprenticeship recruitment team/Curriculum Leaders at FE college of the progression pathways and of the relationship between background and choice of apprenticeship pathway.

A separate analysis looking at data from the National Collaborative Outreach Programme (NCOP) for 2017/2018 for schools in local area and comparing this with data from 2017/2018 for Engineering Apprentices at the FE college suggests that some schools have an overrepresentation of NCOP learners taking up Apprenticeships (for example a school with a target ward population of $20 \%$ however, $68 \%$ of apprentices from the school are from target wards as defined by NCOP) and others a significant underrepresentation when compared to the percentage of age 13-16 target ward learners attending the school. This in turn would suggest that there may be differentials in careers advice and guidance and supports the comments made by apprenticeship recruitment centre staff.

\section{CONCLUSIONS}

The impact of the study has led to a significant increase (from $11 \%$ to $26 \%$ ) of apprentices from disadvantaged backgrounds entering level 2 technical qualifications in Sept 2017 as well as a raising awareness of the imbalance of backgrounds of students. This has led to a more systemised and rigorous approach to career/progression pathway advice to apprenticeship applicants within the college. Thus, at least for apprentices at this FE college there is more likelihood of those from disadvantaged backgrounds having progression opportunities to HE.

The next phase of the project is being funded by Southern Universities Network (SUNet) and is entitled "Understanding the reasons for, and barriers to, a career choice of technical apprenticeships". As highlighted by this project there would appear to be a wider issue with careers advice and guidance and this study sets out to understand the perceptions and knowledge about technical apprenticeships of young people studying at level 2 in year 10 and 11 .

\section{REFERENCES}

[1] Humphries-Smith T., White M. and Hunt C. 2017. Engineering Design, Apprenticeships \& Diversity. In: E\&PDE 2017: 19th International Conference on Engineering and Product Design Education, 7-8 September 2017, Oslo, Norway.

[2] Humphries-Smith T. and Hunt C. 2017. An exploration of progression rates of widening participation students on to an Integrated Master of Engineering. International Journal of Higher Education, 6 (4).

[3] Apprenticeships Guide, https://www.gov.uk/apprenticeships-guide.

[4] UK Government, (2016) What Qualification Levels Mean. Available: https://www.gov.uk/whatdifferent-qualification-levels-mean/list-of-qualification-levels [Accessed on 14th February 2019].

[5] IET Engineering and Technology Skills and Demand in Industry 2017. Access on $30^{\text {th }}$ October 2018 at https://www.theiet.org/factfiles/education/skills2017-page.cfm. 
[6] Engineering UK 2018 Report. Accessed on 30 $0^{\text {th }}$ October 2018 at https://www.engineeringuk.com/media/1576/7444_enguk18_synopsis_standalone_aw.pdf.

[7] Office for Students (2018) POLAR Map of Young Participation Areas. Available: https://www.officeforstudents.org.uk/data-and-analysis/polar-participation-of-local-areas/map-ofyoung-participation-areas/ [Accessed on $14^{\text {th }}$ February 2019].

[8] Fuller et al (2017) Better Apprenticeships Access, quality and labour market outcomes in the English apprenticeship system, Sutton Trust.

[9] Kashefpakdel E.T. and Rehill J. 2018, Teenage apprenticeships: converting awareness to recruitment, London: Education and Research, London.

[10] Hunt C., Collins B., Wardrop A. Hutchings M., Heaslip V. and Pritchard C. 2018. First- and second-generation design and engineering students: experience, attainment and factors influencing them to attend university, Higher Education Research \& Development, 37 (1).

[11] Brockmann M. and Laurie, I. 2016. Apprenticeship in England - the continued role of the academic-vocational divide in shaping learner identities, Journal of Vocational Education and Training, 68 (2).

[12] DfE, 2017. Careers Strategy: making the most of everyone's skills and talents. Available: https://assets.publishing.service.gov.uk/government/uploads/system/uploads/attachment_data/file /664319/Careers_strategy.pdf [Accessed on 7th May 2019]. 